\title{
Article
}

\section{Safety in maritime oil sector: Content analysis of machinery space fire hazards}

John, G.A. and Ikeagwuani, U.M.

Available at http://clok.uclan.ac.uk/5914/

John, G.A. ORCID: 0000-0002-5016-5909 and Ikeagwuani, U.M. (2013) Safety in maritime oil sector: Content analysis of machinery space fire hazards.

Safety Science, 51 (1). pp. 347-353. ISSN 0925-7535

It is advisable to refer to the publisher's version if you intend to cite from the work. http://dx.doi.org/10.1016/j.ssci.2012.08.003

For more information about UCLan's research in this area go to

http://www.uclan.ac.uk/researchgroups/ and search for <name of research Group>.

For information about Research generally at UCLan please go to

http://www.uclan.ac.uk/research/

All outputs in CLoK are protected by Intellectual Property Rights law, including Copyright law. Copyright, IPR and Moral Rights for the works on this site are retained by the individual authors and/or other copyright owners. Terms and conditions for use of this material are defined in the policies page.

\section{CLoK}

Central Lancashire online Knowledge www.clok.uclan.ac.uk

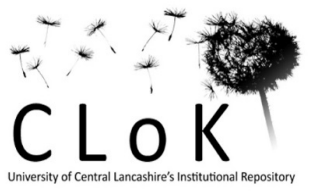




\title{
Safety in maritime oil sector: Content analysis of machinery space fire hazards
}

\begin{abstract}
An in-depth study of the practises within the maritime oil industry was undertaken to ascertain safety issues in seafaring vessels. It was more concentrated on the type of accidents that occur in machine spaces of seafaring vessels in this industry. The main focus of the research was streamlined to fire in machinery spaces. The literature review later concentrated on two of such incidences, they are oil spill and fire events. An investigation was done to assess those factors which actually contribute or are in association to fire outbreak. A content analysis methodology was used to investigate the associative relationships to fire outbreak with the aid of NVivo 9.0 software. The investigation focused on 15 key in-depth reports on machinery space incidences which were uploaded into the software. The results indicate that leakages on hot surfaces were the major causes of fire hazards in seafaring vessels. The results from using this methodology also highlighted two more fire hazards that were not so apparent in previous studies. They are generator fire and compressors fire. The results supported other studies about leakages on hot surfaces as a major contributor, but also clearly show that there are other hazardous factors of fire in machinery spaces that require further investigation.
\end{abstract}




\subsection{Introduction}

The study seeks to understand health and safety issues in the workplace in relation to causes of fire outbreak in machinery spaces of seafaring going vessels. The investigation is based on those that contribute or are in association to fire events on sea vessels. This has been recognized due to continuous technological changes and advancement with regards to vessel design, and complex machinery space configuration. Vessels are seen to be exposed to high risk level of hazards such as fire outbreak and explosion which can further lead to fatality, vessel destruction and environmental pollution. These issues have prompted the need for continuous research into such hazards that can be encountered on sea vessels used for the transportation of oil products.

Lu and Tsai (2008) explain that the environmental conditions of the sea ranks the highest of all hazards with respect to assessment of risks to cases of vessel and cargo loss or damage, injuries and fatalities. According to IMO (2006), the sea has been recognised as a potential and hazardous occupation. In the area of oil spill, Hong et al (2010) writes that due to the fast development in maritime industry with respect to vessels that engage in shipping of oil derivatives, oil spill has become of significance importance. This according to the authors is of major human concern which poses a major threat to the ecosystem. Regulations that have been put in place have aided in making sure that most vessels are built in view of safety and constructed to minimise the level of oil spill incidences when accidents occur (Psarros et al, 2011).

The aspect of fire hazard is the main focus of this paper, with specific reference to machinery spaces. Fire event occur most times as a result of little detail going wrong (DNV, 2007). They further imply that it is difficult avoiding its occurrence in the absences of comprehensive data and lack of experience on tackling such incidences. The avoidance of these occurrences involves practises directed to safety which embraces regulations and maritime industry recommendations (IMCA, 
2003). Evegren (2010) indicates that in the past, most maritime regulations are often initiated reactively after a problem has occurred. This implies that the decisions forming the regulations have been reactive instead of proactive. In view of these problems, the Formal Safety Assessment (FSA) Methodology (Ventikos and Psaraftis, 2004) was developed. The method was initiated by the International Maritime Organisation (IMO) as a body that holds the responsibility directed to maritime welfare worldwide. The main idea of the FSA is more focused on reducing uncertainties to "as low as reasonably practicable" (ALARP), but does not infer that the chances of risk has been reduced (Trbojevic, 2000). However, for the FSA to reduce risk to ALARP, it will adopt techniques that can identify hazards, assess risk, measure cost benefit and make proficient decisions (Wang, 2002). The ALARP principle according to Rosqvist and Tuomien (2004) is the most accepted decision rule in risk informed decision making. Its effect basically leads to a more focused approach to precaution (Trbojevic, 2000). Furthermore, the author indicates that taking precaution in itself reduces risk. Kontovas (2005) writes that the need for risk identification and analysis tools is for tackling risk issues, which ensures a more informed decision making with regards to dwelling on incidences experienced in the past and making the whole process more proactive. Once the hazards has been prioritise, one can then safely carry out the full SFA.

This is achieved by using a content analysis qualitative method in place of scientific methods to assess fire incident reports in vessels in other to derive the desired samples for investigation. The methodology according to Lee and Kim (2001) is used for making inferences from secondary data in a systematic, qualitative and objective manner in other to evaluate variables that are of interest. The qualitative content analysis normally relies on software programs like NVivo 9.0 which will assist in organising, managing and coding the incidents reports in a more proficient manner (Zhang and Wildemuth, 2009). Further analysis will be done using graphical solutions to understand the relationships of the discovered hazards to fire. 
The rest of the paper is the literature review on health and safety in the maritime industry within seafaring vessels, and establishing the gap that exist in the identification of hazards for a FSA analysis; the methodology chosen to carry out the study; the results obtained from the study and the discussion and conclusion.

\subsection{Safety Practises in the Maritime arm of the Oil and Gas Sector.}

Oil operations are divided into three main groups namely, the 'upstream' (oil exploration, drilling and extraction), refining and transportation phase (Alemagi, 2007). The initial stage involves practises such as remote sensing alongside satellite mapping techniques which has seismic techniques used for the identification of potential oil reserves. The second stage is the refining of crude to produce commercial products such as gasoline and other oil derivatives PetroStrategies, 2000). The transportation stage is the main focus of the research, in regards to fire hazards that can be encountered in the shipping of oil and gas. The IMO observes that operations in this area are regarded as one of the most dangerous sectors when compared with other big industries (Alemagi, 2007). Furthermore, it is advisable that key stakeholders in the maritime transportation industry need to improve the health and safety culture within individual organizations (Celik, 2009). This is further seen in reports which show serious injuries and drowning amongst personnel in the seafaring operations ranging from 11.5 to 278 times more than the average fatality rates amongst the general workforce ashore (Havold, 2010). Knudsen and Hassler (2011) states that there are three unarguable facts that relates to safety and environment protection in world shipping,

Vast reduction in the amount of marine accidents worldwide for several decades now,

Adoption of new conventions by the IMO to regulate marine traffic as well as making sure that these new conventions are well implemented, 
Deficiency in the implementation of IMO regulations due to unreliable data which has led to differences in the findings (i.e. data for shipping accidents)

Bejan (2010) believes that even with a well-developed framework with regards to international standards of safety at sea and maritime environmental protection, several owners and countries still indulge in breaking the rules even though this framework exists within the IMO and International Labour Organization (ILO). Such negligence often times endangers the lives of crew members and the environment while considering only their own benefits. Trbojevic and Carr (2000) in a research undertaken, observed that a proposal was made by the United Kingdom Marine Safety Agency (MSA) to the IMO in relation to the application of the Formal Safety Assessment (FSA)which could be applied to ensure that certain strategies are put in place for safety and pollution prevention. The FSA has been explained as a way of identifying risks, analysing these risks and looking at how best such risk could be managed in a cost-effective manner. In order to facilitate the decision making process of the IMO, with regards to new regulations for the shipping industry, this methodology was created (Wang, 2001). The author further explains that the method is valuable when optimising risks of hazards to as low as reasonably practicable. Ventikos and Psaraftis (2004) from their view under the IMO regulations indicates that the process of the FSA commences with describing the issues to be investigated, putting into consideration the limitations and reasons for such constraints. The implementation should be in line with contemporary requirements and with the presence of good knowledge of operation while considering all the aspects like on-board systems/ functions, ships and accident categories when implementing. The FSA consists of the following steps;

$>$ Identification of hazards,

$>$ Risk Assessment,

$>$ Risk control options,

$>$ Cost benefit assessment and

$>$ Recommendation for Decision Making. 
The application of the process has to be highlighted in such a way that it will reflect issues like vessel type, the hazard category of the vessel being investigated so as to integrate all necessary aspects in the study. A unique model should be adopted which explores collective systems in the nature of management; organisational structure, human competence, hardware and electronic aspects so as to recognise their importance and not be used for analysis focused on individual vessel or procedure alone. However, in the case of human error, Soares and Teixeira (2001) advices for an orderly treatment of the FSA as foreseen that human element is one of the major contributor to the causes and avoidances of accidents which the FSA identifies. They further explain that a comprehensive data which involves cases of operational failure, incidence reports, and near misses is needed for making more accurate, cost saving and practical decisions. Wang (2001) notes that the IMO ceaselessly continues to solve issues which are related to operations, survey, management and responsibilities of the governing body itself. However, the author indicates that for these problems to be reduced there will be a need to embrace the FSA which may;

$>$ Offer a system for protecting and regulating events that could lead to unplanned occurrences,

Endeavour that in recent ships, performance is improved and the experience gathered from previous incidences are unified into making efficient decisions for future progress,

Continuous improvement on recent ships so as to measure the change between new and old fleets based in relation to design.

\subsection{Safety on Vessel with Regards to Oil Spill}

A study by Vanem et al (2008) of oil and chemical spills in US waters between 1980 and 2001 leads to the conclusions that, oil spill has a greater number of occurrences compared to chemical and other related spills for shipping activities. The total cost of recovering such incidence comes in two classifications. Psarros et al (2011) explains this further by pointing out the initial as environmental damage as a result of dilapidation of the natural resources which leads to a drop in their services/ the 
cost of control measures of removing the oil e.g. (personnel and equipments). The second instance according to the author is focused more on the losses and damages related to money and property of stakeholders of those in tourism and fisheries which adds to claims on a third party level in an acceptable scheme for compensation. Kirby and Law (2010) mentions that more focused scientific and technological development is aimed at finding solutions to preventing the effects of ship spills, outlining options for treatment as using chemical oil dispersants, bioremediation products, sorbents and manual recovery (Kirby and Law, 2008), stating that using controls measures like chemical oil dispersant can have a positive influence to the health of the practitioner and the ecosystem (Lessard and Demarco, 2000).From a different point of view, Ventikos et al (2004) suggest an acceptable approach for avoiding oil spill as prevention in itself. Further implying that facing the outcome of such consequences won't be an option compared to avoiding a polluting incident or accident which is safer. Alternative technologies that can be used to prevent oil spill according to Dalton and Jin (2010) is the adoption of a double hull vessels which has been seen as a way of reducing the severity and being efficient in avoiding large spills which has been in comparison with a single hull vessel.This new design of ships was not acceptable to some ship owners like the Greek, who from their view explain that the design of double hull is not a solution for pollution avoidance and safety compliance (Goulielmos, 2001). According to stakeholder from Greek, British and Dutch diplomats, Thebault (2004) writes that a shortage of oil supply to demand might erupt because of reduced number of supply vessels which are of double hull specification since single hull vessels are to be phased out.This is based on the speculation of the rate at which the phased out single hull vessels will be replaced with the new specification considering their tonnage. The strategy for the approach of double hull according to Wang (2006) or mid-deck structural requirement for recent vessels came into legislature after the incidence of Exxon Valdez which occurred in 1989 causing a lot of damage. 


\subsection{Safety on Vessels with Regards to Fire}

Fire that is activated by any likely ignition sources like open flames, sparks, leakage and other known sources, which can be as a result of oil spill or flammable materials (Pulaet al, 2006).The guiding rules for fire protection on vessels have been adjusted very often in the Safety of Life at Sea (SOLAS) regulations which is contained in chapter II-2 of SOLAS convention (Lois, 2004). A safety assessment had been carried out in order to make safety requirements more redefined, simple and contemporary for new ships which have led to a comprehensive revision of such regulations. The International Marine Contractors Association IMCA (2003) in an article explains that "machinery spaces are, by their very nature, the most susceptible of all shipboard compartments to serious fires", which is the major area of concentration for this study. Comparison has shown that two third of fire breakouts starts from the engine room which is situated in the machinery spaces of vessels Det Norske VeritasDNV (2007).In addition to this, they write that $56 \%$ involvement of all fire breakouts in engine rooms excluding cases of ship repairs were ignited by leakages of oil onto hot surfaces. Ships could be crippled or destroyed by the exposure of hot oil which can arise as a result of diesel fuel, lubricating oil, hydraulic oil spills Cote (2003).DNV (2007) indicates that associated cost of engine room fire can be equated to between 1 to 4 million USD for cargo vessels compared to passenger ships including the cost of off-hire and loss of image which are summed up in the amount and are irreplaceable. They further gave a statistics of causes within a ship that can erupt fire which are hazards for crew members on duty in such places and also fire fighters as represented below with oil leakage having the highest propensity to cause such outbreak. 


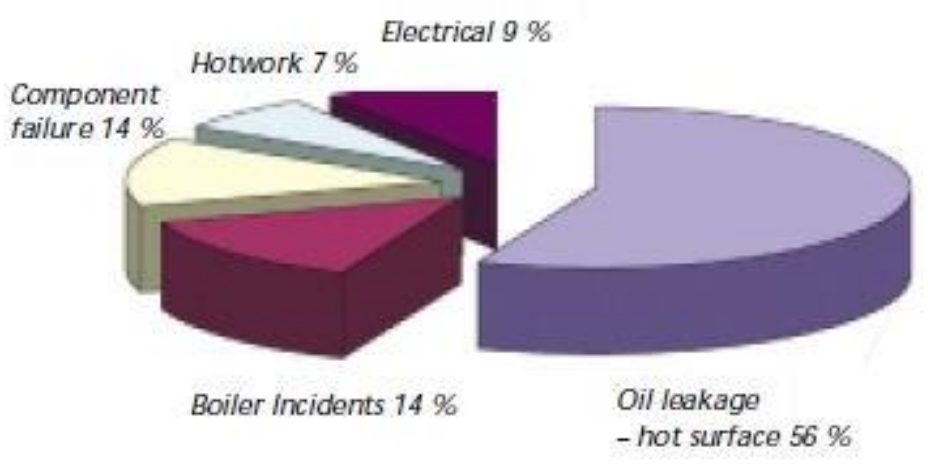

Causes of Fire (Source: DNV, 2007).

Set-off actions for unforeseen incidences are common around human error aspects in vessels (Evegren, 2010). IMO (2002) defines it as "a departure from acceptable or desirable practice on the part of an individual or a group of individuals that can result in unacceptable or undesirable results". Authors like Rothblum (2002) describes human errors from a different angle, suggesting it can be as a result of a wrong decision, inappropriate executed task or inappropriate/ uncompleted action. Mitigation processes for such unplanned incidences from Atherton (2000) view is a well-planned/ operative extinguishing and fire detection system, side by side with a thoroughly trained crew which will balance the designed fire mitigation and operating measures in fire circulation reduction that will basically cut down the damage to properties and harm to life when fire ignites.

\subsection{Hazards on Ships}

The IMO (2007) has listed some hazards that are potential sources of ignition on vessels which can lead to fire outbreak. As the study focuses on machinery spaces of vessels, a list of factors that are susceptible to ignition has to be considered in the work of Evegren (2010) and IMO (2007) to estimate the risk of fire that occur in this particular compartment. This are;

General: Hazards that can lead to fire: Friction, hot surface, radio waves, naked flame, electric arc, incendiary spark. 
Deck areas: Events that can create hazards: Deck lighting, hot work sparking, funnel exhaust emissions.

Accommodation space: Factors that can lead trigger events: Laundry facilities e.g., washing machines, tumble driers, irons etc. Electronic navigational devices.

Machinery spaces: Equipments which are susceptible to fire hazards: Generator engine exhaust manifold, air compressor units.

\subsubsection{Hazard Identification and Risk Analysis Techniques}

There are different techniques for identifying risk in vessels in relation to hazards. They are;

- What-if-analysis - The methodology HSE (2000) can be used to assess any part of a process by engaging in brainstorming. The number of participants increases depending on the size of task. One criterion for this method is that it uses experienced examiners that can detect hazards which when omitted, could lead to an inadequate evaluation.

- Hazard and operability - HSE (2005) defines it to be a process hazard identification. HAZOP is used for assessing potential hazards from failure in a process and at the same time identify them. It deals more on the hazards caused by nonconformity of normal operating conditions.

- Failure Mode and effects Analysis (FMEA) - Webb and Lamoureux (2003) describe FMEA as an inductive approach used for re-examining a part of an overall system which is the physical sub-system component. Its main need is for assessing mechanical and electrical devices like fire suppression devices.

- Fault Tree Analysis - HSE (2000) summarizes FTA as a combination of faults that can lead to an unwanted event. The development of an FTA according to Kontovas (2005) adopts a top to bottom style, putting into consideration the causes of the events under the top level or maybe 
two or move events need to transpire to affect the next scenario. This is normally explained using the fault logic and logic gate.

- Formal Safety Assessment (FSA) - this is dealt with in detail in the next section

\subsubsection{Formal Safety Assessment (FSA)}

The formal safety assessment is a methodology normally used and may be the most appropriate assessment technique in the maritime industry for optimizing risk to ALARP. Hu et al (2007) explains that the methodology has a more validated approach compared to the traditional approach of decision making which the latter is more of "regulation by disaster". The methodology of this guideline has a 5 step process as listed earlier which the IMO (2007) has explained that, the generic model will have to consider the collection of systems which will include management, operational, human, organizational, electronically and hardware characteristics to fulfill the defined functions and not to be viewed as a single entity (ship).

\section{Step 1 - Hazard Identification}

IMO (2007) indicates that the first step is focused on identifying hazards which/ when can take place, and ranking them according to their level of threat. By using standard practices, those that can engage in accidents can be screened and spotted out using data available and making objective decisions afterwards. Ventikos and Psaraftis (2004)writes that the HAZID stage uses a combination of both creative and analytical techniques giving examples as Human Risk Assessment (HRA), statistical analysis, expert judgement, etc.

\section{Step 2 - Risk Analysis}

Risk analysis focuses on the more important scenarios identified in the first step. IMO (2007) writes that it is based on investigating the causes and outcome of associated risks. This is done by using the best methods that will model those risks. It is believed that using these models, more attention will be 
focused on those risks with higher tendency so as to identify and evaluate those actions that makes them occur.

\section{Step 3 - Risk Control Options}

Wang (2002) writes that the target of RCO's is to minimize the occurrences or prevent chances of failures, and can be achieved using structural evaluation methods to identify existing control options for decision making which will reduce cost. IMO (2007) explains that existing risks created by new technology and updated methods of management and operation will have to be considered when creating risk control options.

\section{Step 4 - Cost Benefit Assessment (CBA)}

This stage concentrates on those costs that are needed to implement each Risk Control Options (RCO) mentioned in stage three. IMO (2007) guideline summarises it as focusing on identifying and comparing the benefits and costs of executing risks control options. The definition of cost according to IMO may include initial cost, operating, inspection, decommissioning, certification, training, etc. and should be expressed as life cycle cost when referring to costs, while injuries, environmental damages, reduction in fatalities, indemnity of third party etc. may include benefits and an enhancement in standard life of ships.

\section{Step 5 - Recommendations for Decision Making}

Recommendation at this stage is a critical review focused on comparing and aligning all the mentioned hazards with their causes. Wang (2002) indicates this step aims as making decisions and giving recommendations for safety improvement. The information generated can be used to assist in the choice of cost-effective and equitable changes and to select the best risk control option.

The literature cites that there have been continuous lapses in the IMO conventions of which the governing body earnestly try to curb. Majority of them domicile on ship owners who do not adhere to the stipulated regulations, thereby creating gaps for the IMO on having a comprehensive data of 
those hazards that result to ship accidents e.g., fire.However, this can result to loss of life for crew members or image of any organization. Majority of this fire hazards investigated by different authors commences from the machinery space of vessels, because of the very nature of the compartment which makes it susceptible to such hazard.Furthermore, to reduce the probability of occurrence, different risk models have been used overtime until the new regulation of FSA came into practise. This has been seen to have a precise approach which considers past, present and future occurrences when making decisions.

\subsection{Methodology}

The paper seeks to find the most appropriate method/ design for investigating the major causes of fire in machinery spaces of vessels from incidence reports. Content analysis is seen as a more conducive methodology for this study because it tends to adopt a design which revisits existing data without having to be a participatory researcher in the field. However, it relies on secondary data which is used to build theory and evaluate information, unlike other research methods which depend on questionnaires or interviews (i.e. case study, ethnography). The deductive approach will be used because previous data is available and needs to be reassessed from a different view by a researcher (Catanzaro 1988). The system according to Krippendorff (2004) is what is known as from general to particular, explaining that they are logically conclusive. This approach according to (Polit and Beck, 2004; Hsieh and Shannon, 2005) concentrates on more recent documents, reports or materials in general. However, the documents will be transcribed to create samples with the aid of computer software (NVivo 9.0), assigning keywords to categories to be investigated and coding them as a form of classification to indicate their level of severity. However, for the other methods, responses from respondents via interviews and questionnaire are the backbone for sample generation. 


\subsection{Sampling Criteria}

The study involves a content analysis of a sample of 15 incidences at sea Reports which are more directed to fire hazards on vessels with particular references to machinery space. This will be evaluated using content analysis method to understand the different views in the maritime industry on the causes of fire in machinery spaces and which of these triggering actions has the highest number of references. It will focus more on general assessment of opinions related to the causes of such hazards (i.e. excluding human factors, foundering, injuries to crews and collision and grounding) and not directed to answering any research questions.

\subsection{Content Analysis of Machinery Space Fires}

Report of engine room/ machinery space fires were downloaded from the Marine Accident Investigation Branch (MAIB), (13), Marine Accident Investigation Section (MAIS), (1) and Strategy European Research Cooperation on Maritime Safety (SURSHIP), (1).This was imported into NVivo software, version 9.0- Qualitative Solutions and Research (QSR) Pty. Ltd. NVivo is related to NUD*IST (Non-Numerical Unstructured Data Indexing, Search and Theorizing) and a package for qualitative software research (SAGE, 2011). It makes provision for coding and recovery of coded materials, searching and theorizing with the potential to annotate and edit materials. The keywords used for investigating this hazards should be related to fire or have the same meaning (Elo and Kyngas 2008).

\subsection{Coding Strategy}

Reference to causes of fire was coded into 7 categories which were assigned in their respective nodes. This was done by inserting the keywords into the search query and carefully analysing the context of each paragraph to originate those that contribute to fire hazard. However, each reference 
made was saved into their corresponding nodes, putting into consideration the number of sources in which they appear.

Table 1: Reference to Machinery Space Hazards from Reports

\begin{tabular}{|l|l|l|}
\hline Hazards & Sources & References \\
\hline boilers & 2 & 4 \\
\hline component failures & 9 & 41 \\
\hline compressors & 1 & 1 \\
\hline electrical & 5 & 8 \\
\hline generators & 3 & 4 \\
\hline hot work & 5 & 23 \\
leakages and hot surface & 10 & 63 \\
\hline
\end{tabular}

\subsection{Data Analysis and Discussion}

In other to make it clearer to understand, data presentations have been adopted using graphical solutions to analyse the sample results. The representation of the outcome of each hazard originated from reports is to have an understanding of the number of reports that have made reference to particular hazard cases as a source of ignition. In addition, another investigation was done to evaluate which of these hazards has the highest contribution to fire outbreak.

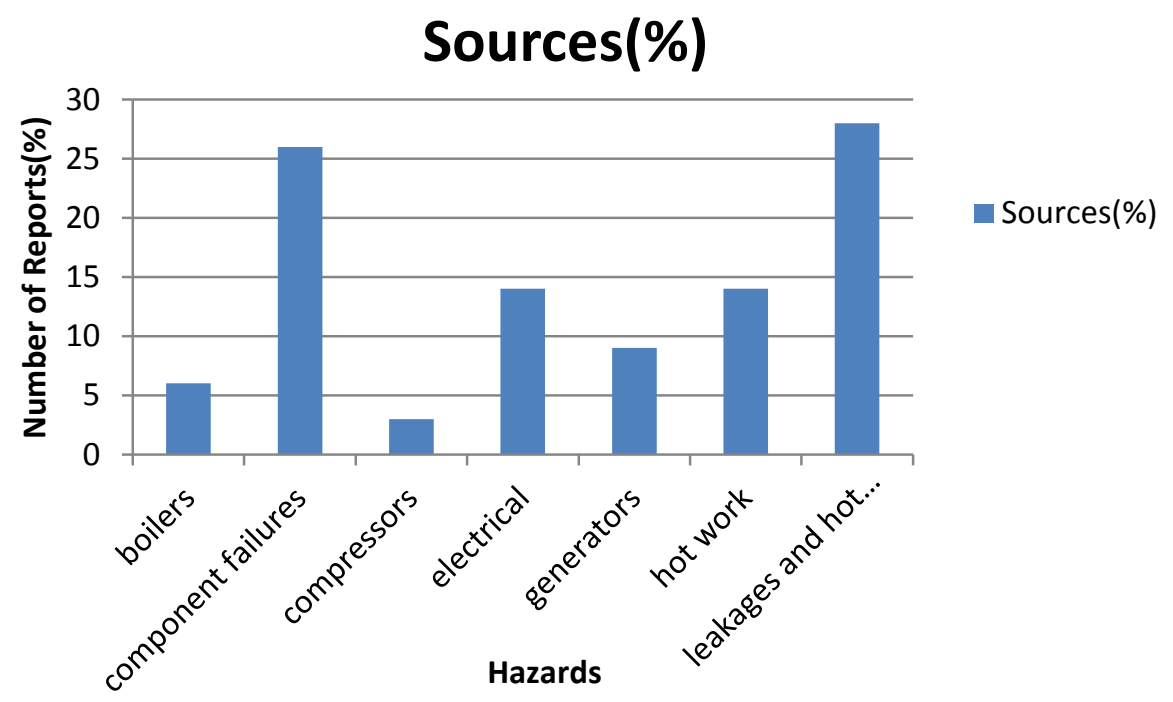

Graph of Hazards against Outcome in Reports 
The illustration above depicts the frequency of appearances for hazards discovered in the reports used for investigation. Each of these hazards is known to have an association or contribute to the causes of machinery space fires. Leakages and hot surfaces is seen to have appeared in 10 out of the total 15 reports which can be equated to $29 \%$ of the overall data used for the investigation. Component failures covered $26 \%$ as the second highest issue deliberated on. This was also a major issue that was made reference to in 9 of the reports. However, both electrical incidences and hot works have 14\% each, of which cases as ignition sources was made reference to in 5 of the reports used for assessment. Furthermore, boiler incidences, compressors and generators had coverages of $6 \%, 3 \%$ and $8 \%$ consecutively having in one way or the other contributed or associated to fire incidences.

\section{Fire Hazards}

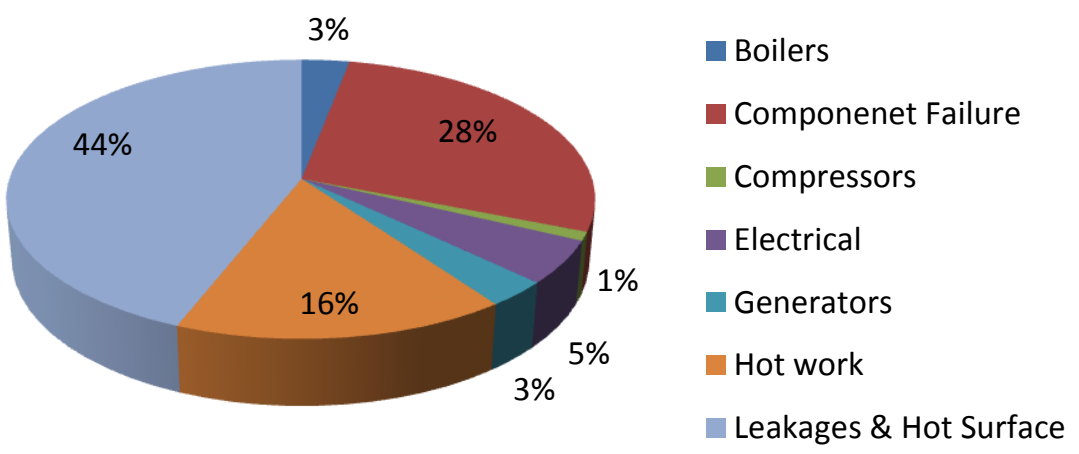

\section{Hazard Association in Igniting Fire}

Causes of fire incidences in machinery spaces have been graded according on how susceptible they are to fire. This was based on the investigation taken which led to the realization of the results shown in the above diagram. Hot works as shown, has a $16 \%$ chance of igniting fires in engine rooms, which is of high risk compared to some other hazards. This is not as porous as component failure event which has a $28 \%$ chance, also with leakages and hot surfaces indicated as the major causes of 
machinery fire incidences with $44 \%$. The remaining hazards, though reference has been made to them as having little possibilities of causing fire, they still associate or contribute to such incidences one way or the other.

The investigation results on compressor incidences as susceptible to fire were not too common. However, the finding shows that it has a minimum probability of $1 \%$ chance of causing fire which does not conclude that it is not to be taken seriously. Literatures such as DNV, (2007) have indicated no evidence of such occurrences or have been considered unimportant due to its minimal association to machinery space fire. For generators, $8 \%$ of the reports have made references to fire incidences caused by the mechanical device. This indicates that generators have a $3 \%$ chance of causing machinery space fires. It has been noted as high risk due to its nature. Boilers have been identified by DNV (2007) as susceptible to fire, which also contributes to $14 \%$ of machinery space fire.The research in its findings also revealed that $14 \%$ of the overall reports gave instances of electrical failure hazards. It is discovered to have $5 \%$ chance of igniting fire. Based on the analysis, it can be agreed that leakages and hot surfaces have the most potential to ignite fires. The paper also mentioned the presence of new hazards compared to researches done by DNV (2007) that should be put into consideration (i.e. Generators and Compressors) which overtime can have a high significance level in relation to resulting in machinery space fire.

\subsection{Conclusion}

The issue of fire and explosion has been the background of the study and has been identified that machinery space is an area were fire erupts due to the nature of its compartment. Fire is caused by substances or mechanical failures which the IMO has indicated. For reducing this event, it has been specified that SOLAS had revised its regulation a couple of times in the view of enhancing safety practise. Different stakeholders have taken on the study in machinery spaces and it was discovered that leakages of oil on hot surfaces has the highest potential of fires occurrences. To revisit this case, this study used a content analysis methodology. This was with the aid of Qualitative Research 
software QRS NVivo 9.0, which resulted in the same outcome. The interesting finding was that other hazards were seen to be having presence in the association or contribution to fire incidences. Such hazards were not indicated in other studies (i.e. generators and compressors). The discussion on these hazards identifies that in as much as they have a minimum presence in contributing to fire; its activities can as well lead to fire and explosion on the long-run. However, there is need to reduce such occurrences to as "low as reasonable practicable" or eliminate them according to the ALARP philosophy. Failures and uncertainties that can lead to machinery fires can be tackled using hazard identification and risk techniques and also proposing control options for reducing their likelihood.

Further research is advised into the causes of machinery space fires due to the fact that this study has used a minimum number of reports for its investigation compared to the likes of DNV. The underlying reason is that leakages of oil on hot surfaces have been viewed from the direction of machinery spaces. Furthermore, it does not conclude that there is an absence of human elements to its causation and can be as a result of poor housekeeping. In addition, a more holistic approach can be adopted using quantitative technique to evaluate the impacts of fire hazards and by giving a more concise control options with the use of numerics. This can be achieved by involving a cost benefit assessment to understand the cost saving involved in preventing these risks from occurring compared to when they actually happen. Finally, it has been identified that a hazard can contribute to fire outbreak, there might be a need for further research on incidences were possibilities of different hazards (i.e. three or more) might contribute to such fire incidences. The study shows the effectiveness of using content analysis in exposing major contributors to fire hazards in machinery spaces. This small sample research showed that the use of content analysis is an effective technique for extracting information from health and safety reports and databases on a large scale. 


\section{References}

Alemagi, D. (2007). 'The Oil Industry along The Atlantic Coast of Cameroon: Assessing Impacts and Possible Solutions', Resources policy, 32(3), pp. 135-145

Atherton, J.G. (2000). 'The Cause and Prevention of Marine Fires', Sea trade Cruise Shipping Convention 2000, Miami Beach Convention Centre Florida, March

Bejan, R. (2010). 'Research Regarding the Causes of Maritime Disasters to Oil Tankers in Order to Enhance Maritime Safety', Maritime Transport \& Navigation Journal, 2(2), Available at: http://www.ronomar.ro/resource/maredu/issue2_paper6.pdf (Accessed June 24, 2011)

Catanzaro, M. (1998).Using Qualitative Analytical Techniques.In Nursing Research. Theory and Practice,C. V. Mosby, St Louis

Celik, M. (2009). 'Designing of Integrated Quality and Safety Management System (IQSMS) for Shipping Operation', Safety Science, 47(5), pp. 569-577

Cote, A.E. (2003). Operation of Fire Protection Systems, National Fire Protection Association, Jones \&Bartlett Learning, Massachusetts, USA

Dalton, T. and Jin, D. (2010). 'Extent and frequency of vessel oil spills in US marine protected areas', Marine Pollution Bulletin,60(11), pp. 1939-1945

Det Norske Veritas (2007). 'Engine Room Fires can be Avoided, Managing Risk', Available from: http://exchange.dnv.com/Documentation/Maritime/FireSafety/FIRE\%20mappe\%202.qxd.pdf, (Accessed 20 July 2011)

Elo, S. and Kynga, S. H. (2008). 'The Qualitative Content Analysis Process', Journal of Advanced Nursing62(1), pp. 107-115

Evegren, F. (2010).Assessing Fire Safety in Maritime Composite Superstructures - A Risk-Based Approach, Report 5327, Lund.

Goulielmos,A.M. (2001). 'Maritime safety: facts and proposals for the European OPA', Disaster Prevention and Management, 10(4), pp. 278-285.

Hong, X., Chen, W. and Zhang, L. (2010). 'International Society for Environmental Information Sciences 2010 Annual Conference (ISEIS): A probabilistic Risk Forecast of Accidental Oil Spills from Vessels in Luoyuan Bay, Fujian Province, PRC', Procedia Environmental Sciences, 2(1) pp. 4956

HSE, (2000).Review of Hazard Identification Techniques, Available at: http://www.hse.gov.uk/research/hsl_pdf/2005/hs10558.pdf, (Accessed 24 August 2011)

HSE, (2005). 'Review of Hazard Identification Techniques', Available at: http://www.hse.gov.uk/research/hs1_pdf/2005/hs10558.pdf, (Accessed 9 August 2011)

Hsieh, H.F and Shannon, S.E. (2005). 'Three Approaches to Qualitative Content Analysis', Qualitative Health Research, 15(9), pp. 1277-1288

Hu, S., Fang, Q., Xia, H. and Xi, Y. (2007). 'Formal Safety Assessment Based on Relative Risks Model in Ship Navigation', Reliability Engineering and System Safety, 92(3), pp. 369-377 
IMCA, (2003).Fires in Machinery Spaces on DP Vessels, Available at: http://www.imca-int.com/documents/divisions/marine/docs/IMCAM119.pdf (Accessed 6 August 2011)

IMO, (2006).MARPOL Consolidated Edition 2006: Articles, Protocols, Annexes, Unified Interpretations of the International Convention for the Prevention of Pollution from Ships, 1973, as Modified by the Protocol of 1978 Relating Thereto. IMO, London

IMO, (2007).Consolidated text of the guidelines for formal safety assessment (FSA) for use in the IMO rule-making process, (MSC/Circ.1023-MEPC/Circ.392)

Ikeagwuani U. M (2011) Safety in the maritime oil sector: a content analysis approach of machinery space fire hazards. Unpublished MSc dissertation, submitted to the University of Central Lancashire, School of Built and Natural Environment, Preston, UK

Kirby, M.F. and Law, R.J. (2008). 'Oil Spill Treatment Products Approval: the UK Approach and Potential Application to the Gulf region', Marine Pollution Bulletin,56(7) pp.1243-1247

Kirby, M.F. and Law, R.J. (2010). 'Accidental Spill at Sea-Risk, Impact, Mitigation and the Need for Co-ordination Post- Incident Monitoring', Marine Pollution Bulletin, 60(6), pp. 797-803

Knudsen, O. F. and Hassler, B. (2011). 'IMO Legislation and its Implementation: Accident Risk, Vessel Deficiencies and National Administrative Practices', Marine Policy,35(2), pp. 201-207

Kontovas, C.A. (2005). Formal Safety Assessment Critical Review and Future Role, Division of Ship and Marine Transport, Available at: http://www.martrans.org/docs/theses/kontovas.pdf (Assessed 6 August 2011

Krippendorff, K. (2004) Content analysis: an introduction to its methodology, SAGE

Lee, J.HandKim, Y.G. (2001), 'A Stage Model of Organizational Knowledge Management: A Latent Content Analysis', Expert Systems with Applications, 20(4), pp. 299-311

Lessard, R.R. and DeMarco, G. (2000), 'The Significance of Oil Spill Dispersants', Spill Science \& Technology Bulletin,6(1),pp.59-68

Lois, P., Wang, J., Wall, A. and Ruxton, T. (2004). 'Formal Safety Assessment of Cruise Ships', Tourism Management, 25(1), pp. 93-109

Lu, C.H and Tsai, C.L. (2008). 'The Effects of Safety Climate on Vessel Accidents in the Container Shipping Context', Accident Analysis and Prevention, 40(2), pp. 594-601

Petro Strategies, Inc., (2000) Refining, Available at:

http://www.petrostrategies.org/Learning_Center/refining.htm\#Refinery\%20Economics, (Accessed 7September 2011)

Polit D.F. and Beck C.T. (2004).Nursing Research.Principles and Methods. Lippincott Williams \& Wilkins, Philadelphia, PA

Psarros, G., Skjong, R. and Vanem, E. (2011). 'Risk Acceptance Criterion for Tanker Oil Spill Risk 
Reduction Measures', Marine Pollution and Bulletin,62(1)pp. 116-127

Pula, R., Khan, F.I., Veitch, B. and Amyotte, P.R. (2006). 'A Grid Based Approach for Fire and Explosion Consequence Analysis’, Process Safety and Environmental protection, 84(2), pp. 79-91

Rosqvist, T. and Tuominen, R. (2004). 'Qualification of Formal Safety Assessment: An Exploratory Study', Safety Science, $\mathbf{4 2}(2)$, pp. 99-120

Rothblum, A.M. (2002). 'Human error and marine safety, Maritime Human Factors Conference', Available at: http://www.geovs.com/_UPLOADED/Human\%20Error\%20and\%20Marine\%20Safety.pdf, (Accessed 3 August 2011)

SAGE, (2011).Research Methods Online, Available at: http://srmo.sagepub.com/view/the-sage-dictionary-of-social-research-methods/n163.xml (Accessed 25 September 2011)

Soares, C.J. and Teixeira, A.P. (2001). 'Risk Assessment in Maritime Transportation', Reliability Engineering \& System Safety, 74(3), pp. 299-309

Thebault, L. (2004). 'Maritime safety culture in Europe', Managerial Law, 46(1), pp. 1-59

Trbojevic, V. M. and Carr, B. J. (2000). 'Risk Based Methodology for Safety Improvements in Ports', Journal of Hazardous Materials, 71(1-3, 7),pp. 467-480

Vanem, E., Endresen, O. and Skjong, R. (2008). 'Cost-Effectiveness Criteria for Marine Oil Spill Preventive Measures', Reliability Engineering and System Safety,93(9) pp.1354-1368

Ventikos, N.P. and Psaraftis, H.N. (2004). Spill Accidents Modelling: A Critical Survey of the Event Decision network in the Context of IMO's Formal Safety Assessment', Journal of Hazardous Materials, 107(1-2, 27), pp. 59-66

Wang, J. (2001).' The Current Status and Future Aspects in Formal Ship Safety Assessment', Safety Science,38(1), pp. 19-30.

Wang, J. (2002). 'Offshore Safety Case Approach and Formal Safety Assessment of Ships', Journal of Safety Research, 33(1), pp. 81- 115

Wang, J. (2006). 'Maritime Risk Assessment and its Current Status', Quality and Reliability Engineering International, 22(1), pp. 3-19

Webb, R.D.G. and Lamoureux, T.M. (2003).Human Reliability and Ship Stability, Human Systems Incorporated, Available at: http://pubs.drdc.gc.ca/PDFS/unc18/p521120.pdf, (Accessed 8 September 2011)

Zhang, Y. and Wildemuth, B.M. (2009).Qualitative Analysis of Content, Available at: http://ils.unc.edu/ yanz/Content_analysis.pdf , (Accessed 3 September 2011) 